\title{
Frequency distribution of IL-17A G197A (rs2275913) and IL-17F A7488G (rs763780) polymorphisms among healthy Sudanese population
}

\author{
Nouh S. Mohamed ${ }^{1,2,3^{*}} \mathbb{D}$, Emmanuel E. Siddig ${ }^{2,4,5}$, Abdallah E. Ahmed ${ }^{2}$, Musab M. A. Albsheer ${ }^{3}$, \\ Hanadi Abdelbagi ${ }^{6}$, Eman T. Ali ${ }^{7}$, Anadel A. Alsubki ${ }^{1}$, Sabah A. Abdalaziz ${ }^{1}$, Madinna Mustafa', \\ Mohamed S. Muneer ${ }^{8,9,10}$, Hussam A. Osman', Maha M. Osman², Mohamed S. Ali ${ }^{11}$, Ali M. M. Edris 7,12 , \\ Ayman Ahmed ${ }^{13}$ and Rihab A. Omer ${ }^{14}$
}

\begin{abstract}
Objectives: IL-17A G197A and IL-17F A7488G polymorphisms has been identified to be associated with the susceptibility to many diseases. This study aimed to investigate the frequency distribution of IL-17A G197A and IL-17F A7488G polymorphisms among healthy Sudanese population. A descriptive cross-sectional hospital-based molecular study conducted in different sites throughout Sudan. Two ml blood samples were collected from 717 healthy participants. Demographic data and the medical history of the participants were collected.

Results: Of the 717 participants, 355 (49.5\%) were males and 362 (50.5\%) were females, their mean age was $30.2 \pm 17.2$ and $32.2 \pm 16.5$, respectively. For IL-17A, the most frequent genotype detected among males and females was IL-17A heterozygote allele (AG); 215 (60.6\%) and 194 (53.6\%), respectively. Whereas, for IL-17F, the most frequent allele among males and females was the homozygote allele (AA); 298 (83.9\%) for males and 322 (89.0\%) for females. HWE for genotype distributions of IL-17A was showing statistical insignificance for IL-17A among males and females, $P$ value 0.614. While HWE for IL-17F reached the equilibrium level, $P$ value 0.048 . The most frequent age group was those aged between 21 to 40 years; 281 (39.2\%). Arab constituted the major ethnicity of the study participants; 418 (58.3\%), P value 0.034
\end{abstract}

Keywords: Interleukin 17A, Interleukin 17F, Polymorphism, Healthy population, Sudan

\section{Introduction}

$\mathrm{T}$ helper 17 (Th17) cells, is one of the CD4 T helper cells lineages that been defined as a unique effector subset of cells [1], in particular through the production of Interleukins (ILs) mainly $I L-17 A$ and $I L-17 F[1,2]$. The $I L-17$ family of cytokines contains other 4 members including;

\footnotetext{
*Correspondence: nouh_saad@outlook.com

${ }^{1}$ Department of Parasitology and Medical Entomology, Faculty of Medical

Laboratory Sciences, Nile University, Khartoum, Sudan

Full list of author information is available at the end of the article
}

$I L-17 B, I L-17 C, I L-17 D$, and $I L-17 E$ [2]. Both $I L-17 A$ and $I L-17 F$ are considered as inflammation-related genes [3]. Although little is known about most of the $I L-17$ family members, $I L-17 F$ was discovered to share the strongest homology to $I L-17 A$. The previous report on $I L-17 A$ and $I L-17 F$ in inducing the expression of other various adhesion molecules, cytokines, and chemokines was reported [4]. Previously, polymorphisms of $I L-17 A$ G197A (rs2275913) and IL-17F A7488G (rs763780) were found to be associated with the increased susceptibility to rheumatoid arthritis and ulcerative colitis, respectively 
[5, 6]. Also, $I L-17 A$ and $I L-17 F$ were investigated in gastric cancer risks and the association of each single nucleotide polymorphism (SNP) with subtypes of gastric cancer according to its clinicopathological features and their roles in prognosis [7]. $I L-17 A$ and $I L-17 F$ have also been associated with the pathogenesis of a growing list of autoimmune and inflammatory diseases, such as inflammatory bowel diseases and psoriasis $[8,9]$. Several studies have found excess expression of $I L-17 A$ in various tumor tissues, including prostate cancer, colorectal cancer, breast cancer, and gastric cancer [10-13]. Moreover, increasing evidence suggested the role of $I L-17 A$ in Helicobacter pylori-related gastric diseases [14, 15].

In Sudan, no study has ever investigated the frequency distribution of $I L-17 A$ G197A (rs2275913) and $I L-17 F$ $A 7488 G$ (rs763780) polymorphisms among the Sudanese population. In a previous study conducted by Wu et al. [7] provided the first evidence that the $I L-17 F$ A7488G coding variant increases gastric cancer risks in a low-risk Chinese population, and revealed its association with subtypes of clinicopathologic features of the gastric cancer patients. Studies are needed to investigate the distribution of IL-17A G197A (rs2275913) and IL-17F A7488G (rs763780) polymorphisms. Also, the result of the known population structure of this gene has implications for understanding the epidemiology not only of cancer, but also the increased susceptibility towards gastric inflammations in Sudan, and the potentials for more effective treatment therapy. In this study, we aimed to determine the frequency of $I L-17 A$ G197A (rs2275913) and $I L-17 F$ A7488G (rs763780) polymorphisms among a healthy Sudanese population.

\section{Main text \\ Materials and methods \\ Study design, study sites, samples and data collection}

This is a descriptive cross-sectional hospital-based molecular study conducted in different sites throughout Sudan including; Khartoum and Madani (central region); New Halfa, Port Sudan, and Gedaref (eastern region); River Nile (North region); and Ad Damazin and Kosti (southern region). Two $\mathrm{ml}$ blood samples were collected from 717 healthy participants recruited at the health facilities of each site. Blood samples were preserved in sodium citrate blood containers. Demographic data and the medical history of the participants were collected. Participation in this study was fully voluntary, and only individuals who expressed interest willingly to participate in this study by signing a written informed consent form were included in the study. Pregnant women, children aged less than 1 year, participants with a history of ulcerative colitis and rheumatoid arthritis, beside immunecompromised patients were excluded from the study to reduce hemoglobin loss in case of pregnant women and infants and to avoid bias in the results of SNPs frequency distribution in case of those with history of ulcerative colitis and rheumatoid arthritis.

PCR-RFLP for IL-17F A7488G and IL-17A G197A genotyping The genomic DNA was extracted from blood samples using QIAamp DNA blood Mini Kit (Qiagen Inc., Germany). DNA was re-suspended in $200 \mu$ of $1 \mathrm{X}$ TE-buffer and stored at $-20{ }^{\circ} \mathrm{C}$ until molecular investigations. $I L-17 A$ G197A and $I L-17 F$ A7488G genotyping was performed by polymerase chain reaction-restriction fragment length polymorphism (PCR-RFLP). Primers used for IL-17A G197A and IL-17F A7488G were as follows: sense 5-AACAAGTAAGAATGAAAAGAGGAC ATGGT-3 and anti-sense 5-CCCCCAATGAGGTCA TAGAAGAATC-3 for $I L-17 A$; sense 5-ACCAAGGCT GCTCTGTTTCT-3 and anti-sense 5-GGTAAGGAG TGGCATTTCTA-3 for $I L-17 F$ as described previously [7]. The PCR amplification was performed in a total volume of $25 \mu \mathrm{l}$ mixture containing using single tube PCR i-Taq premix (iNtRON Biotechnology, Korea), mixed with $1 \mu \mathrm{l}$ genomic DNA, and $1 \mu \mathrm{M}$ of each primer and incubated in $\mathrm{MJ}$ research thermocycler (USA) using the previously described amplification condition [7]. PCR products were digested overnight at $37{ }^{\circ} \mathrm{C}$ with $\mathrm{XagI}$ and NIaIII (New England BioLabs, England) to determine the genotypes of $I L-17 A$ G197A and IL-17F A7488G, respectively. Digested amplicons were separated using $3 \%$ agarose gel electrophoresis. To confirm the genotyping results, randomly selected PCR products were sequenced using Sanger deoxy ribonucleic acid sequencing method using ABI 3730 sequencing system provided by BGI company (BGI, China).

\section{Statistical analysis}

Data were analyzed using the Statistical Package for the Social Sciences (SPSS v20). Hardy-Weinberg equilibrium (HWE) was performed using Pearson's $\chi^{2}$ test. Differences in allele frequency were analyzed using Fisher's exact test, a $\mathrm{P}$ value $<0.05$ was considered significant. The sequences of $I L-17 A$ and $I L-17 F$ products were analyzed using BioEdit v7 software for the confirmation of sequences polymorphisms.

\section{Results}

\section{PCR-RFLP and sequencing results}

Amplified PCR products of each of $I L-17 A$ G197A and $I L-17 F$ A7488G bands sizes were 102 and 143 base pairs (bp), respectively. The results of enzyme digestion using XagI and NIaIII produced several fragments grouped into 3 types of fragments (Fig. 1). 


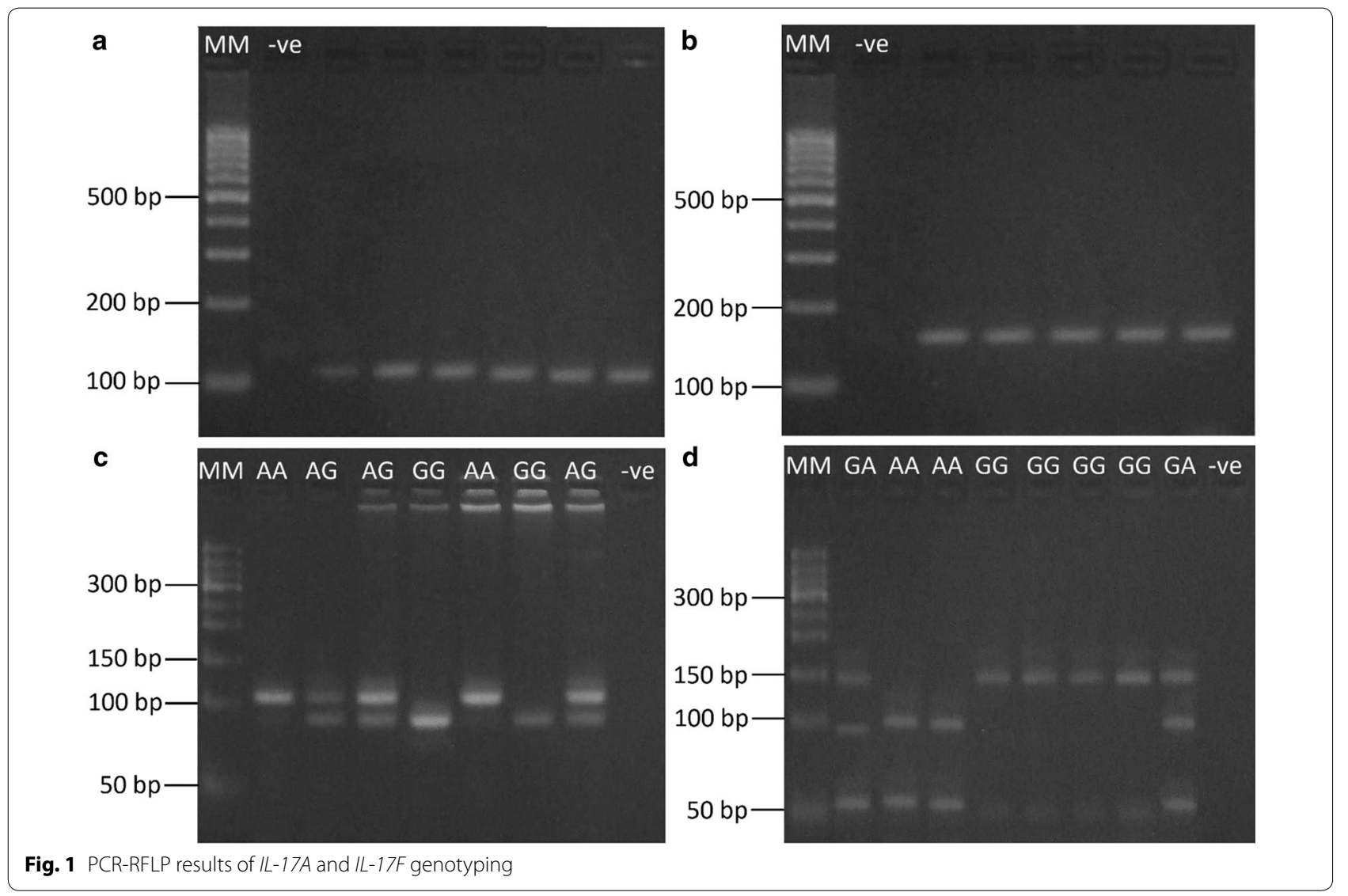

The selected samples were accurately confirming the cutting sites of each enzyme, and showing the correct SNP (Fig. 2).

\section{Frequency of IL-17A G197A and IL-17F A7488G genotypes}

In this study a total of 717 healthy participants were included. 355 (49.5\%) were males and 362 (50.5\%) were females, their mean age was $30.2 \pm 17.2$ and $32.2 \pm 16.5$, respectively.

For $I L-17 A$, the most frequent genotype detected among males and females was $I L-17 A$ heterozygote allele (AG); $215(60.6 \%)$ and 194 (53.6\%), respectively. Whereas, for $I L-17 F$, the most frequent allele among males and females was the homozygote allele (AA); 298 (83.9\%) for males and $322(89.0 \%)$ for females. No statistical significance association for frequency distribution of the different $I L-17 A$ and $I L-17 F$ genotypes based on gender, $\mathrm{P}$ values were 0.113 and 0.136 , respectively. HWE for genotype distributions of $I L-17 A$ was showing statistical insignificance for $I L-17 A$ among males and females, HWE (Fisher exact test $=0.614$ ). While HWE for $I L$ $17 F$ reached the equilibrium level, HWE (Fisher exact test $=0.048)$.
Based on age groups, the most frequent age group was those aged between 21 to 40 years; 281 (39.2\%), followed by participants aged between 1 to 21 years; 188 (26.2\%). Concerning the ethnicity, Arab constituted the major ethnicity of the study participants; 418 (58.3\%). Frequency distribution across the different ethnic groups was statistically significant for $I L-17 A$ genotypes, $\mathrm{P}$ value 0.034 (Table 1).

The subgroup analysis of IL-17A and IL-17F genotypes distribution across the different ethic groups revealed a statistically significant difference of IL-17A genotypes among Arabs compared to the different ethic groups (See Additional file 1). Whereas, no statistically significant difference obtained for IL-17F genotypes distribution across the different Sudanese ethnic groups (Additional file 2).

\section{Discussion}

The polymorphisms of $I L-17 A$ G197A (rs2275913) and IL-17F A7488G (rs763780) has been associated with susceptibility to various types of proinflammatory diseases and gastric cancer [5-7]. Additionally, knowing the population structure of this gene was noted to be uniquely beneficial in means of treatment and understanding diseases prognosis [16]. In this study, we aimed to 
a

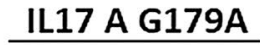

GA

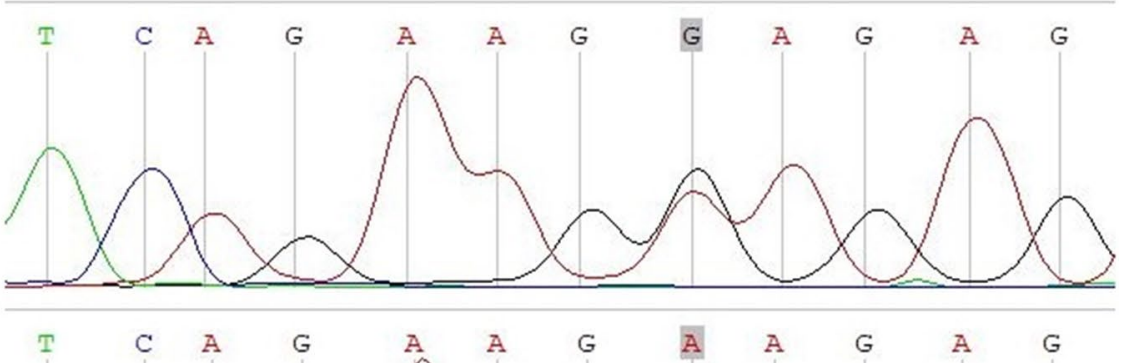

AA

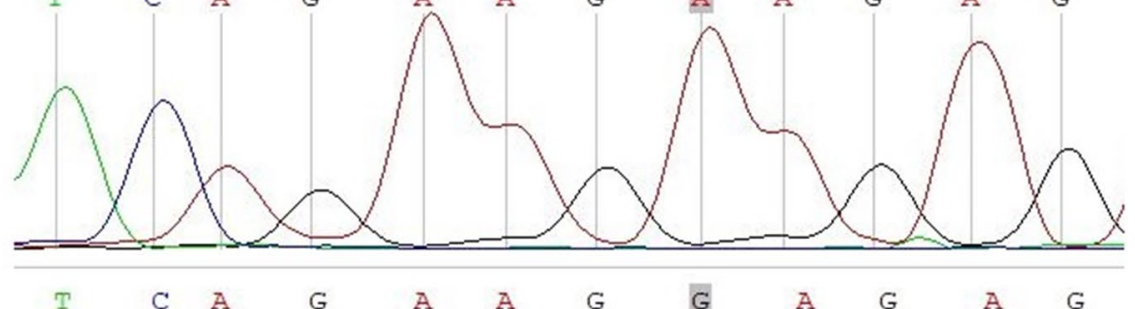

GG

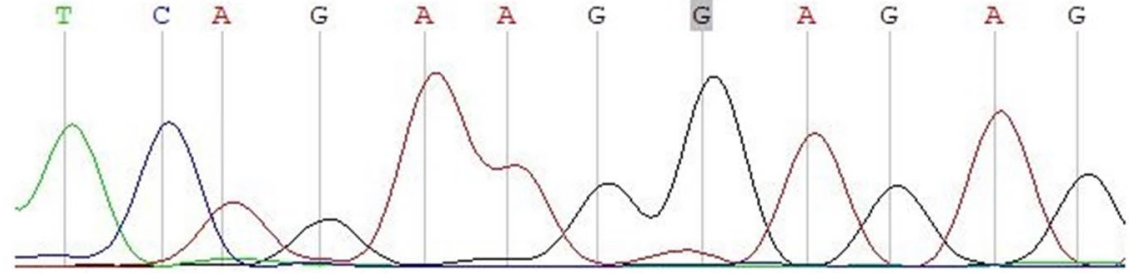

AG
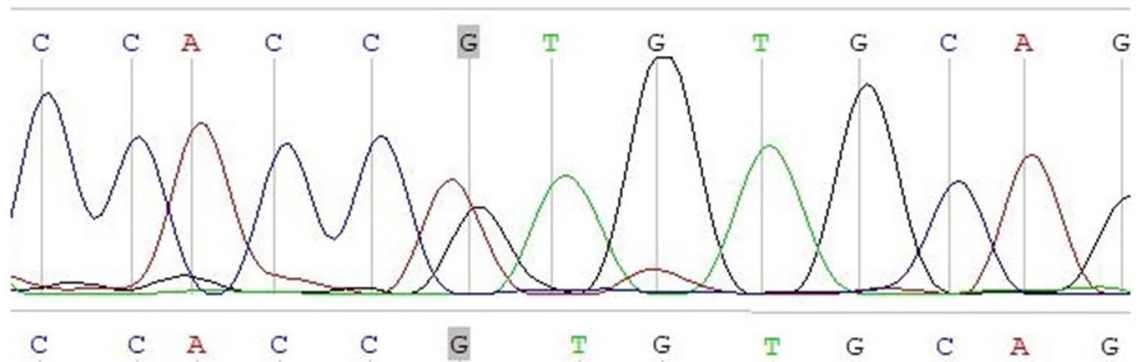

GG

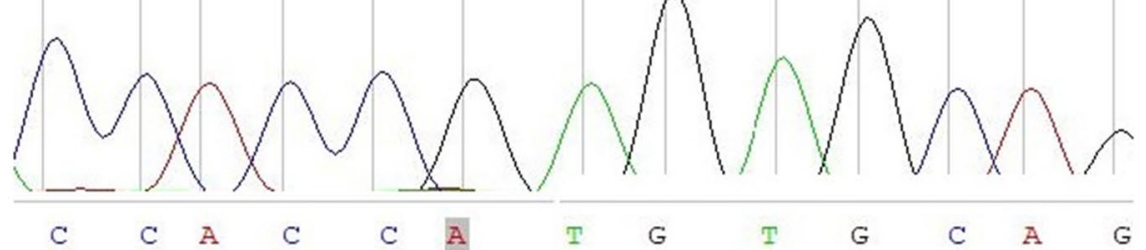

AA

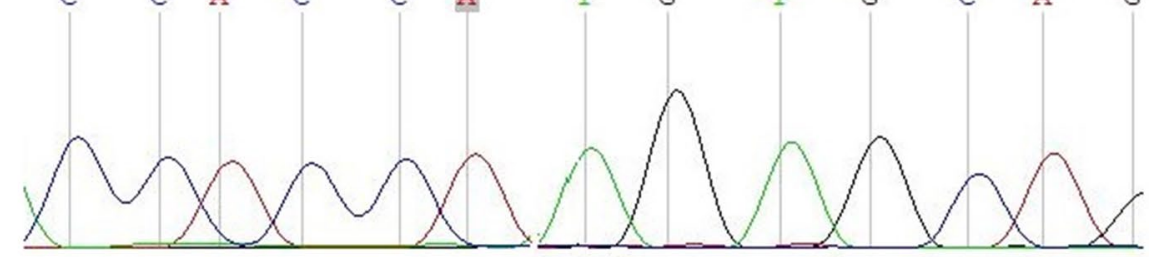

Fig. 2 Sequencing results of the amplified products for $I L-17 A$ and $I L-17 F$ polymorphisms

determine the frequency of $I L-17 A$ and $I L-17 F$ polymorphisms among healthy Sudanese populations. The results obtained in this study, revealed that the distribution of
$I L-17 A$ and $I L-17 F$ was statistically insignificant among males and females. This agreeing with previously conducted studies $[17,18]$. Although, the study participants 
Table 1 Frequency distribution of $I L-17 A$ and $I L-17 F$ genotypes among participants gender, age groups and participants ethnicity

\begin{tabular}{|c|c|c|c|c|c|c|c|c|c|}
\hline & \multicolumn{4}{|c|}{ IL-17 A genotypes no. (\%) } & \multicolumn{4}{|c|}{ IL-17 F genotypes no. (\%) } & \multirow[t]{2}{*}{ Total } \\
\hline & AA & AG & GG & $\mathbf{P}^{*}$ & AA & GA & GG & $P^{*}$ & \\
\hline \multicolumn{10}{|l|}{ Gender } \\
\hline Male & $127(35.8)$ & $215(60.6)$ & $13(3.7)$ & 0.113 & $298(83.9)$ & $42(11.8)$ & $15(4.2)$ & 0.136 & $355(49.5)$ \\
\hline Female & $147(40.6)$ & $194(53.6)$ & $21(5.8)$ & & $322(89.0)$ & $28(7.7)$ & $12(3.3)$ & & $362(50.5)$ \\
\hline \multicolumn{10}{|l|}{ Age group } \\
\hline $1-20$ years & $71(37.8)$ & $108(57.4)$ & $9(4.8)$ & 0.977 & $166(88.3)$ & $15(8.0)$ & $7(3.7)$ & 0.231 & $188(26.2)$ \\
\hline $21-40$ years & $110(39.1)$ & $160(56.9)$ & $11(3.9)$ & & $231(82.2)$ & $37(13.2)$ & $13(4.6)$ & & $281(39.2)$ \\
\hline $41-60$ years & $54(40.0)$ & $74(54.8)$ & $7(5.2)$ & & $118(87.4)$ & $13(9.6)$ & $4(3.0)$ & & $135(18.8)$ \\
\hline $61-80$ years & $9(30.0)$ & $19(63.3)$ & $2(6.7)$ & & $29(96.7)$ & $1(3.3)$ & $0(0.0)$ & & $30(4.2)$ \\
\hline $81-100$ years & $30(36.1)$ & $48(57.8)$ & $5(6.0)$ & & $76(91.6)$ & $4(4.8)$ & $3(3.6)$ & & $83(11.6)$ \\
\hline \multicolumn{10}{|l|}{ Ethnicity } \\
\hline Arab & $142(34.0)$ & $257(61.5)$ & $19(4.5)$ & 0.034 & $363(86.8)$ & $40(9.6)$ & 15 (3.6) & 0.992 & $418(58.3)$ \\
\hline Beja & $8(30.8)$ & $16(61.5)$ & $2(7.7)$ & & $23(88.5)$ & $2(7.7)$ & $1(3.8)$ & & $26(3.6)$ \\
\hline Fallata & $8(40.0)$ & $11(55.0)$ & $1(5.0)$ & & $17(85.0)$ & $3(15.0)$ & $0(0.0)$ & & $20(2.8)$ \\
\hline Fur & $30(50.8)$ & $26(44.1)$ & $3(5.1)$ & & $50(84.7)$ & $6(10.2)$ & $3(5.1)$ & & $59(8.2)$ \\
\hline Nuba & $34(35.1)$ & $59(60.8)$ & $4(4.1)$ & & $82(84.5)$ & $11(11.3)$ & $4(4.1)$ & & $97(13.5)$ \\
\hline Nubian & $52(53.6)$ & $40(41.2)$ & $5(5.2)$ & & 85 (87.6) & $8(8.2)$ & $4(4.1)$ & & $97(13.5)$ \\
\hline
\end{tabular}

${ }^{*}$, P value

were selectively healthy individuals this could provide a hint towards the chance of difference occurrence when including unhealthy individuals diagnosed with gastric cancer, breast cancer or rheumatoid arthritis [7, 17, 19, 20].

Interestingly, this result also supports the fact that this gene could be significantly linked with susceptibly to certain diseases such as $H$. pylori infection [21]. Since $H$. pylori infections reported in Sudan are quietly increasing [22-25], and here, the high frequency of $I L-17 A$ and $I L-$ $17 F$ genotypes can increase the susceptibility towards $H$. pylori infection. However, this assumption needs further investigations.

Regarding, the distribution among the different age groups obtained in this study, although, no association was found, $I L-17 A$ polymorphism has been associated with early TNM staging and poorly differentiated gastric cancers with aging [7]. Moreover, this result showed the degree of population structure for this gene which will help in cancer onset prediction especially among elderly. This was also seen by the small number of elderlies been included hence most elders were diagnosed previously with rheumatoid arthritis and gastric colitis and been excluded from the study. This was in line with the previous hypotheses that $I L-17 A$ polymorphism may influence the development and progression of gastric carcinogenesis [7]. Also, the $I L-17 F 7488 G A$ genotype that reported to increase gastric cancer risk from the age of 40 years [7].
The significant association between $I L-17 A$ and participants ethnicity could be attributed to several factors, remarkably, based on 2009-2010 cancer prevalence in Sudan, $37.8 \%$ of the total cancer patients were diagnosed with breast cancer [26]. Although, less is known about patient's ethnicity, nevertheless based on Mahmoud et al. (unpublished data), the rate of breast and gastric cancer incidence in Sudan since 2010 to 2015 were approximately $20 \%$ and 5\% respectively. Among both cancer groups, $60 \%$ and $70 \%$ were noted to be of Arab ethnicity (unpublished data). This is suggesting that $I L-17 A$ polymorphism is taking role in cancer susceptibility among different Sudanese ethnic groups. This was well discussed previously by $\mathrm{Li}$ et al. [21], indicating the role of ethnicity in gastric cancer susceptibly, where found that $I L-17 A$ increases gastric cancer susceptibility among Japanese population but not with the Chinese population.

This study highlights the need for further investigations towards addressing $I L-17 A$ and $I L-17 F$ polymorphisms among Sudanese population diagnosed with different types of cancers, in order to further understand the role of this SNP polymorphism in cancer susceptibility and further cancer incidence. However, such prediction could also be ambiguous and misleading since cancer susceptibility may not be linked to a single nucleotide polymorphism at a single gene $[27,28]$. 


\section{Conclusion}

This study provides the first data on the Sudanese population structure on $I L-17 A$ and $I L-17 F$ gene polymorphisms. This might be of help to identify the association of these polymorphisms with different patients' groups and could benefit in the understanding of those genes' involvement in caner or other types of diseases susceptibility.

\section{Limitations}

- This study focused on healthy Sudanese participants, limiting the natural variation within the population structure, which might be biasly selected against the $I L-17 A$ and $I L-17 F$ polymorphisms and resulted in the underestimation of their prevalence. Therefore, the need for more diverse study population including unhealthy population is extremely important to further understand the role of these SNPs in different diseases' susceptibility.

\section{Supplementary information}

Supplementary information accompanies this paper at https://doi. org/10.1186/s13104-020-05165-4.

Additional file 1: Table S1. Subgroup analysis of IL-17A genotypes distribution across the different Sudanese ethnic groups.

Additional file 2: Table S2. Subgroup analysis of IL-17F genotypes distribution across the different Sudanese ethnic groups. M \pm Std: Mean Difference \pm Standard Error. 95\% Cl [L-U]: 95\% Confidence Interval [ Lower bound-Upper bound].

\section{Abbreviations}

HWE: Hardy-Weinberg Equilibrium; ILs: Interleukins; PCR-RFLP: Polymerase Chain Reaction-Restriction Fragment Length Polymorphism; SNP: Single Nucleotide Polymorphism; SPSS: Statistical Package for Social Sciences; Th17: Thelper 17.

\section{Acknowledgements}

We would like to thank all health centers' staff for their kind collaboration and assistance. And also great thanks to all participants contributed to this work.

\section{Authors' contributions}

NSM, EES, and RAO provided conceptual framework for the project. AEA, MMAA, HA, ETA, and AA guidance for interpretation of the data, performed data analysis. AAA, SAA, MM, MSM, HAO and MMO participated in the molecular performance. NSM, MSA, and AMME performed the statistical analysis and guidance for data interpretation. All authors read and approved the final manuscript.

\section{Funding}

Not applicable.

\section{Availability of data and materials}

The datasets used and/or analyzed during the current study are available from the corresponding author on reasonable request.

\section{Ethics approval and consent to participate}

The protocol was approved by the Ethical Committee of Nile University Research Ethics Committee. Informed consent was obtained from each participant prior to enrollment using writing and verbal informed consent in case of illiterate patients.

\section{Consent to publish}

Not applicable.

\section{Competing interests}

The authors declare that they have no competing interests.

\section{Author details}

${ }^{1}$ Department of Parasitology and Medical Entomology, Faculty of Medical Laboratory Sciences, Nile University, Khartoum, Sudan. ${ }^{2}$ Alfarrabi College for Science and Technology, Khartoum, Sudan. ${ }^{3}$ Department of Parasitology and Medical Entomology, Faculty of Medicine, Sinnar University, Sinnar, Sudan. ${ }^{4}$ School of Medicine, Nile University, Khartoum, Sudan. ${ }^{5}$ Mycetoma Research Center, University of Khartoum, Khartoum, Sudan. ${ }^{6}$ Department of Biotechnology, School of Pharmacy, Ahfad University for Women, Omdurman, Sudan. ${ }^{7}$ Department of Histopathology and Cytology, Faculty of Medical Laboratory Sciences, University of Khartoum, Khartoum, Sudan. ${ }^{8}$ Department of Neurology, Mayo Clinic, Jacksonville, FL, USA. ${ }^{9}$ Department of Radiology, Mayo Clinic, Jacksonville, FL, USA. ${ }^{10}$ Department of Internal Medicine, Faculty of Medicine, University of Khartoum, Khartoum, Sudan. ${ }^{11}$ Faculty of Medicine, Neelain University, Khartoum, Sudan. ${ }^{12}$ Department of Histopathology and Cytology, Faculty of Applied Medical Sciences, University of Bisha, Bisha, Kingdom of Saudi Arabia. ${ }^{13}$ Institute of Endemic Diseases, University of Khartoum, Khartoum, Sudan. ${ }^{14}$ Department of Molecular Biology, Institute of Parasitology, University of Leipzig, Leipzig, Germany.

Received: 25 May 2020 Accepted: 29 June 2020

Published online: 02 July 2020

\section{References}

1. Harrington LE, Hatton RD, Mangan PR, Turner H, Murphy TL, Murphy KM, Weaver CT. Interleukin 17-producing CD4+ effector T cells develop via a lineage distinct from the Thelper type 1 and 2 lineages. Nat Immunol. 2005:6:1123-32.

2. Park H, Li Z, Yang XO, Chang SH, Nurieva R, Wang Y-H, Wang Y, Hood L, Zhu Z, Tian Q. A distinct lineage of CD4 T cells regulates tissue inflammation by producing interleukin 17. Nat Immunol. 2005;6:1133.

3. El-Omar EM, Rabkin CS, Gammon MD, Vaughan TL, Risch HA, Schoenberg JB, Stanford JL, Mayne ST, Goedert J, Blot WJ. Increased risk of noncardia gastric cancer associated with proinflammatory cytokine gene polymorphisms. Gastroenterology. 2003;124:1193-201.

4. Hizawa N, Kawaguchi M, Huang SK, Nishimura M. Role of interleukin$17 \mathrm{~F}$ in chronic inflammatory and allergic lung disease. Clin Exp Allergy. 2006;36:1109-14.

5. Nordang GB, Viken MK, Hollis-Moffatt JE, Merriman TR, Førre ØT, Helgetveit K, Kvien TK, Lie BA. Association analysis of the interleukin 17A gene in Caucasian rheumatoid arthritis patients from Norway and New Zealand. Rheumatology. 2009;48:367-70.

6. Arisawa T, Tahara T, Shibata T, Nagasaka M, Nakamura M, Kamiya Y, Fujita $H$, Nakamura M, Yoshioka D, Arima Y. The influence of polymorphisms of interleukin-17A and interleukin-17F genes on the susceptibility to ulcerative colitis. J Clin Immunol. 2008;28:44-9.

7. Wu X, Zeng Z, Chen B, Yu J, Xue L, Hao Y, Chen M, Sung JJ, Hu P. Association between polymorphisms in interleukin-17A and interleukin-17F genes and risks of gastric cancer. Int J Cancer. 2010;127:86-92.

8. Ouyang W, Kolls JK, Zheng Y. The biological functions of T helper 17 cell effector cytokines in inflammation. Immunity. 2008;28:454-67.

9. Wilson NJ, Boniface K, Chan JR, McKenzie BS, Blumenschein WM, Mattson JD, Basham B, Smith K, Chen T, Morel F. Development, cytokine profile and function of human interleukin 17-producing helper T cells. Nat Immunol. 2007;8:950.

10. Steiner GE, Newman ME, PaikI D, Stix U, Memaran-Dagda N, Lee C, Marberger MJ. Expression and function of pro-inflammatory interleukin IL-17 and IL-17 receptor in normal, benign hyperplastic, and malignant prostate. Prostate. 2003;56:171-82. 
11. Le Gouvello S, Bastuji-Garin S, Aloulou N, Mansour H, Chaumette M-T, Berrehar F, Seikour A, Charachon A, Karoui M, Leroy K. High prevalence of Foxp3 and IL17 in MMR-proficient colorectal carcinomas. Gut. 2008;57:772-9.

12. Zhu X, Mulcahy LA, Mohammed RA, Lee AH, Franks HA, Kilpatrick L, Yilmazer A, Paish EC, Ellis IO, Patel PM. IL-17 expression by breast-cancerassociated macrophages: IL-17 promotes invasiveness of breast cancer cell lines. Breast Cancer Res. 2008;10:R95

13. Zhang B, Rong G, Wei H, Zhang M, Bi J, Ma L, Xue X, Wei G, Liu X, Fang $\mathrm{G}$. The prevalence of Th17 cells in patients with gastric cancer. Biochem Biophys Res Commun. 2008;374:533-7.

14. Caruso R, Pallone F, Monteleone G. Emerging role of IL-23/IL-17 axis in H pylori-associated pathology. World J Gastroenterol. 2007;13:5547.

15. Shiomi S, Toriie A, Imamura S, Konishi H, Mitsufuji S, Iwakura Y, Yamaoka Y, Ota H, Yamamoto T, Imanishi J. IL-17 is Involved in Helicobacter pyloriInduced Gastric Inflammatory Responses in a Mouse Model. Helicobacter. 2008;13:518-24

16. Zhang X, Weng W, Xu W, Wang Y, Yu W, Tang X, Ma L, Pan Q, Wang J, Sun F. Prognostic significance of interleukin 17 in cancer: a meta-analysis. Int J Clin Exp Med. 2014;7:3258.

17. Hou C, Yang F. Interleukin-17A gene polymorphism is associated with susceptibility to gastric cancer. Int J Clin Exp Pathol. 2015;8:7378.

18. Białecka M, Ostasz R, Kurzawski M, Klimowicz A, Fabiańczyk H, Bojko P, Dziedziejko V, Safranow K, Machoy-Mokrzyńska A, Droździk M. IL17A and IL17F gene polymorphism association with psoriasis risk and response to treatment in a polish population. Dermatology. 2016;232:592-6.

19. Pawlik A, Kotrych D, Malinowski D, Dziedziejko V, Czerewaty M, Safranow K. IL17A and IL17F gene polymorphisms in patients with rheumatoid arthritis. BMC Musculoskeletal Disord. 2016;17:208.

20. Lyon DE, McCain NL, Walter J, Schubert C. Cytokine comparisons between women with breast cancer and women with a negative breast biopsy. Nurs Res. 2008;57:51.
21. Li X-F, Shen M, Cai J-W, Zeng Y-Q, Li M, Yang G-L, Xu X-M, Hu Y-Y. Association of interleukin-17 gene polymorphisms and Helicobacter pylori infection with gastric cancer susceptibility: a cumulative and comprehensive meta-analysis. Int J Clin Exp Med. 2015;8:17623.

22. Abdallah TM, Mohammed HB, Mohammed MH, Ali AAA. Sero-prevalence and factors associated with Helicobacter pylori infection in Eastern Sudan. Asian Pac J Trop Dis. 2014:4:115-9.

23. Mubarak N, Gasim Gl, Khalafalla KE, Ali NI, Adam I. Helicobacter pylori, anemia, iron deficiency and thrombocytopenia among pregnant women at Khartoum, Sudan. Trans R Soc Trop Med Hygiene. 2014;108:380-4.

24. Osman SM, Mubarak SM, Omer IM, Abdullah MA. Helicobacter pylori infection and the onset of type 1 diabetes mellitus in Sudanese children. Sudanese J Paediatrics. 2016;16:59.

25. Alshareef SA, Rayis DA, Adam I, Gasim Gl. Helicobacter pylori infection, gestational diabetes mellitus and insulin resistance among pregnant Sudanese women. BMC Res Notes. 2018;11:517.

26. Saeed IE, Weng HY, Mohamed KH, Mohammed SI. Cancer incidence in Khartoum, Sudan: first results from the Cancer Registry, 2009-2010. Cancer Med. 2014;3:1075-84.

27. Deng N, Zhou H, Fan H, Yuan Y. Single nucleotide polymorphisms and cancer susceptibility. Oncotarget. 2017;8:110635.

28. Dai Z-M, Zhang T-S, Lin S, Zhang W-G, Liu J, Cao X-M, Li H-B, Wang M, Liu X-H, Liu K. Role of IL-17A rs2275913 and IL-17F rs763780 polymorphisms in risk of cancer development: an updated meta-analysis. Sci Rep. 2016:6:20439.

\section{Publisher's Note}

Springer Nature remains neutral with regard to jurisdictional claims in published maps and institutional affiliations.
Ready to submit your research? Choose BMC and benefit from:

- fast, convenient online submission

- thorough peer review by experienced researchers in your field

- rapid publication on acceptance

- support for research data, including large and complex data types

- gold Open Access which fosters wider collaboration and increased citations

- maximum visibility for your research: over $100 \mathrm{M}$ website views per year

At BMC, research is always in progress.

Learn more biomedcentral.com/submissions 